\title{
Auto-servoventilation in heart failure with sleep apnoea: a randomised controlled trial
}

\author{
Michael Arzt ${ }^{1,7}$, Stephan Schroll17,7, Frederic Series ${ }^{2}, K_{\text {Keir Lewis }}^{3}$, Amit Benjamin $^{3}$, \\ Pierre Escourrou ${ }^{4}$, Ruth Luigart ${ }^{1}$, Victoria Kehl ${ }^{5}$ and Michael Pfeifer ${ }^{1,6}$
}

Affiliations: 'Dept of Internal Medicine II, Division of Respirology, University Hospital Regensburg, Regensburg, ${ }^{5}$ Institute for Medical Statistics and Epidemiology, Technical University Munich, Munich, and ${ }^{6}$ Center for Pneumology, Donaustauf Hospital, Donaustauf, Germany. ${ }^{2}$ Centre de Recherche, IUCPQ, Universite Laval, Quebec, QC, Canada. ${ }^{3}$ Dept of Respiratory Medicine, Prince Philip Hospital and Swansea College of Medicine, Llanelli, UK. ${ }^{4}$ Centrede Medecine du Sommeil, Hopital Antoine Beclere, Clamart, France. ${ }^{7}$ Both authors contributed equally.

Correspondence: M. Arzt, Center for Sleep Medicine, Dept of Internal Medicine II, University Hospital Regensburg, Franz-Josef-Strauss-Allee 11, 93053 Regensburg, Germany. E-mail: michael.arztaukr.de

ABSTRACT We tested the hypotheses that in patients with congestive heart failure (CHF) and sleep disordered breathing (SDB) auto-servoventilation (ASV) improves cardiac function and quality of life.

Between March 2007 and September 2009, patients with stable CHF (left ventricular ejection fraction $(\mathrm{LVEF}) \leqslant 40 \%)$ and SDB (apnoea/hypopnoea index $\geqslant 20$ events $\cdot \mathrm{h}^{-1}$ ) were randomised to receive either ASV (BiPAP ASV (Philips Respironics, Murrysville, PA, USA), $\mathrm{n}=37$ ) and optimal medical management, or optimal medical management alone $(n=35)$. Outcomes were assessed at baseline and 12 weeks.

The apnoea/hypopnoea index assessed with polysomnography scored in one core laboratory was significantly more reduced in the ASV group $\left(-39 \pm 16\right.$ versus $-1 \pm 13$ events $\left.\cdot h^{-1} ; \mathrm{p}<0.001\right)$ with an average use of $4.5 \pm 3.0 \mathrm{~h} \cdot \mathrm{day}^{-1}$. Both groups showed similar improvements of the primary end-point LVEF $(+3.4 \pm 5$ versus $+3.5 \pm 6 \% ; \mathrm{p}=0.915)$ assessed with echocardiography. In the ASV group, reduction of N-terminal probrain natriuretic peptide (NT-proBNP) was significantly greater $\left(-360 \pm 569\right.$ versus $+135 \pm 625 \mathrm{ng} \cdot \mathrm{mL}^{-1}$; $\mathrm{p}=0.010)$. No differences were observed between the groups in subjective quality of life.

In patients with CHF and SDB, ASV reduced NT-proBNP levels, but improvement of LVEF or quality of life was not greater than in the control group. The data support that such patients can be randomised in large-scale, long-term trials of positive airway pressure therapy versus control to determine effects on cardiovascular outcome.

@ERSpublications

Patients with heart failure and sleep apnoea can be randomised in long-term trials of positive airway pressure therapy http://ow.ly/nQnVg

This article has supplementary material available from www.erj.ersjournals.com

Received: May 282012 | Accepted after revision: Nov 232012 | First published online: Dec 062012

Clinical trial: This study is registered at www.controlled-trials.com with identifier number ISRCTN04353156.

Support statement: This work was supported by grant support from Philips Home Healthcare Solutions (Murrysville, PA, USA). The sponsor played no role in design, conduct of the study, or analysis and interpretation of the data. The sponsor played no role in the preparation, review and approval of the manuscript.

Conflict of interest: Disclosures can be found alongside the online version of this article at www.erj.ersjournals.com

Copyright @ERS 2013 


\section{Introduction}

Congestive heart failure (CHF) is associated with repeated hospitalisation, high morbidity and mortality $[1,2]$. The implementation of polypharmaceutical and device therapies has resulted in an improved outcome for patients $[3,4]$. However, symptomatic CHF continues to confer a poor prognosis that is equivalent to some malignancies, with a five-year mortality of 20-50\% [5]. Thus, complimentary, nonpharmaceutical therapies are needed.

One potential therapeutic target in CHF patients is the treatment of any coexistent sleep disordered breathing (SDB). Recent estimates suggest that SDB affects $51-71 \%$ of patients with CHF [6, 7]. The consequences of SDB, such as hypoxia, increased sympathetic drive and cardiac after-load may adversely affect heart function and contribute to the increased morbidity and mortality associated with CHF [8-10]. This increased mortality was not reversible in the largest randomised trial of continuous positive airway pressure (CPAP) for patients with central sleep apnoea (CSA) and CHF [11]. However, a post hoc analysis of this trial [12] demonstrated that those with suppression of CSA by CPAP had marked improvements in left ventricular ejection fraction (LVEF) and transplant-free survival compared with control patients who were not treated with CPAP. These data suggest that adequate suppression of SDB may play a key role in improving cardiovascular outcome in such patients.

Auto-servoventilation (ASV) suppresses CSA better than CPAP therapy, in patients with and without coexisting obstructive sleep apnoea (OSA) $[13,14]$. Randomised trials investigating the short-term effects of ASV on cardiac function in patients with CHF and CSA have been small and their findings inconsistent $[13,15-17]$, with two out of four not showing a significant improvement of LVEF $[15,16]$. However, in the absence of a significant change of LVEF, one trial [16] demonstrated a significant fall of plasma brain natriuretic peptide as a surrogate marker of cardiac function $[2,18]$.

While CHF patients with SDB and SDB-related symptoms usually improve their daytime hypersomnolence and quality of life (QoL) on treatment with positive airway pressure support [19], it is unknown whether SDB should be routinely treated in CHF patients with no or mild SDB-related symptoms. Therefore, we performed a multicentre, randomised, open label, parallel group trial, with blinded and centralised evaluation of outcomes, to test whether in patients with CHF and SDB, with no or mild SDB-related symptoms, additional treatment with ASV improves daytime cardiac function and QoL compared to stable optimal medical management alone.

\section{Methods}

Sample size

The sample size for the primary outcome (LVEF) was calculated using ANOVA, assuming an improvement in LVEF of $4.0 \%$, a standard deviation of 5.0 and a dropout rate of $\sim 15 \%$. Based on these assumptions, at a two-sided alpha of 0.05 , with $80 \%$ power, $\sim 35$ subjects per group were required.

\section{Patients}

Candidates for participation in the trial included patients aged 18-80 years, with CHF (New York Heart Association class II-III) due to ischaemic, nonischaemic or hypertensive cardiomyopathy, a LVEF $\leqslant 40 \%$, stable clinical status and stable optimal medical therapy according to the guidelines of the European Society of Cardiology [2] for at least 4 weeks and an apnoea/hypopnea index (AHI) $\geqslant 20$ events $\cdot \mathrm{h}^{-1}$ of sleep assessed by in-laboratory polysomnography. Patients were excluded if they had unstable angina, myocardial infarction, cardiac surgery or hospital admissions within the previous 3 months, or if they had contraindications for positive airway pressure therapy, were using oxygen therapy, or had severe pulmonary disease or symptoms of SDB that required immediate treatment. All patients gave written informed consent to participate in the trial. The protocol was approved by the local ethics boards of each participating centre. The trial is registered at www.controlled-trials.com (ISRCTN04353156).

\section{Screening}

Polysomnography was performed using the core equipment available at each of the four participating centres (Regensburg, Germany; Laval, Canada; Clamart, France; and Swansea, UK). Thoraco-abdominal effort and airflow were recorded quantitatively by respiratory inductance plethysmography and a nasal pressure cannula [20]. Sleep stages, and apnoea and hypopnoea events were measured, defined and scored according to standard diagnostic criteria, as described previously [20]. The AHI was defined as the number of apnoea and hypopnoea events per hour of sleep. To ensure quality control, a blinded analysis of each sleep study was performed by two experienced sleep technicians. 


\section{Echocardiography}

Transthoracic echocardiographic was performed according to current recommendations for chamber quantification [21]. LVEF was calculated according to a modification of the Simpson method (end-diastolic minus end-systolic volume divided by end-diastolic volume). To ensure quality control, a blinded analysis of each echocardiogram was performed by two experienced analysts.

\section{Randomisation}

Eligible patients were randomly assigned to either the control group, who continued to receive optimal medical management for heart failure, or the ASV group, who received ASV therapy in addition to optimal medical management (1:1). Randomisation was performed using a computerised schedule in random blocks of four and was stratified by type of SDB (i.e. OSA and CSA). Randomisation codes were made available by fax back-request after testing for eligibility for the study.

\section{Initiation of ASV}

By protocol night-time pressure settings had to be in the range of tolerated pressure settings during an attended daytime titration with monitoring of blood pressure and heart rate. During the first night, CPAP was titrated under polysomnographic monitoring from $4 \mathrm{cmH}_{2} \mathrm{O}$ in $1-\mathrm{cmH}_{2} \mathrm{O}$ increments to the point where any sign of flow limitation was eliminated, or to the maximum level the patient could tolerate $\left(\leqslant 10 \mathrm{cmH}_{2} \mathrm{O}\right)$.

Before initiating ASV at night, a daytime titration with bi-level positive airway pressure was performed in order to avoid long-term application of ASV with pressure settings that may lead to haemodynamic compromise. First, baseline blood pressure (BP) and heart rate were recorded as described. Expiratory positive airway pressure was set at the optimal CPAP level suppressing upper airway obstruction determined by polysomnography. Inspiratory pressure support (IPS) was titrated starting at $1 \mathrm{cmH}_{2} \mathrm{O}$ and increasing by $1 \mathrm{cmH}_{2} \mathrm{O}$, up to the maximum of $10 \mathrm{cmH}_{2} \mathrm{O}$, every $5 \mathrm{~min}$ after $\mathrm{BP}$ and heart rate readings were taken. Attended daytime IPS titration was stopped when a pressure of $10 \mathrm{cmH}_{2} \mathrm{O}$ was reached or if mean BP was $<60 \mathrm{mmHg}$ or a drop of $>15 \mathrm{mmHg}$ occurred or the patient did not tolerate IPS.

On the night of ASV initiation, the expiratory positive airway pressure of the ASV device was set to the CPAP determined during the titration night. The minimum inspiratory positive airway pressure was set to the expiratory positive airway pressure level, and the maximum inspiratory positive airway pressure to a maximum of $10 \mathrm{cmH}_{2} \mathrm{O}$ above the expiratory positive airway pressure level, or not higher than the maximum the patient could tolerate during the daytime test. The default backup rate of the machine was used. Assessment of hours of ASV use over this period were obtained from the downloadable SmartCard located in the device.

\section{Measurement of primary and secondary outcomes}

Values from the in laboratory polysomnography and echocardiography tests, performed during screening, were taken as baseline. The primary outcome of the trial was the change in LVEF within 12 weeks of treatment. All secondary outcome measures were performed at baseline and at 12 weeks after randomisation.

Serum samples were stored at $-70^{\circ} \mathrm{C}$ and analysed using standard techniques for measurement of $\mathrm{N}$-terminal pro-brain natriuretic peptide (NT-proBNP) and creatinine in one batch at a central laboratory. Glomerular filtration rate (GFR) was estimated using the four-variable abbreviated modification of diet in renal disease formula.

Two questionnaires were used to assess QoL: the 36-item short form health survey (SF-36) as a generic QoL questionnaire [22]; and the Minnesota Living with Heart Failure Questionnaire (MLHFQ) as a heart failure specific questionnaire [23]. For the SF-36, a score of 0 represented the worst and 100 the best possible health. For the MLHFQ, higher scores indicated more severe impairment. Fatigue was measured using the fatigue severity scale [24]. Higher scores suggest indicated worsening symptoms.

\section{Statistical analysis}

The intention-to-treat (ITT) analysis set contained all randomised patients (fig. 1). Patients who had a significant change in cardiac medication as a competing treatment during the period of the trial may influence the results. Therefore, the per-protocol (PP) set was also analysed. It contained all patients in the ITT set, excluding those who had a change in cardiac medication, prematurely withdrew from the study or received the wrong treatment allocation (fig. 1).

The primary outcome of the trial, change in LVEF within 12 weeks of treatment, was tested with the twosided independent samples t-test at the 5\% significance level. Statistical tests were performed for the 


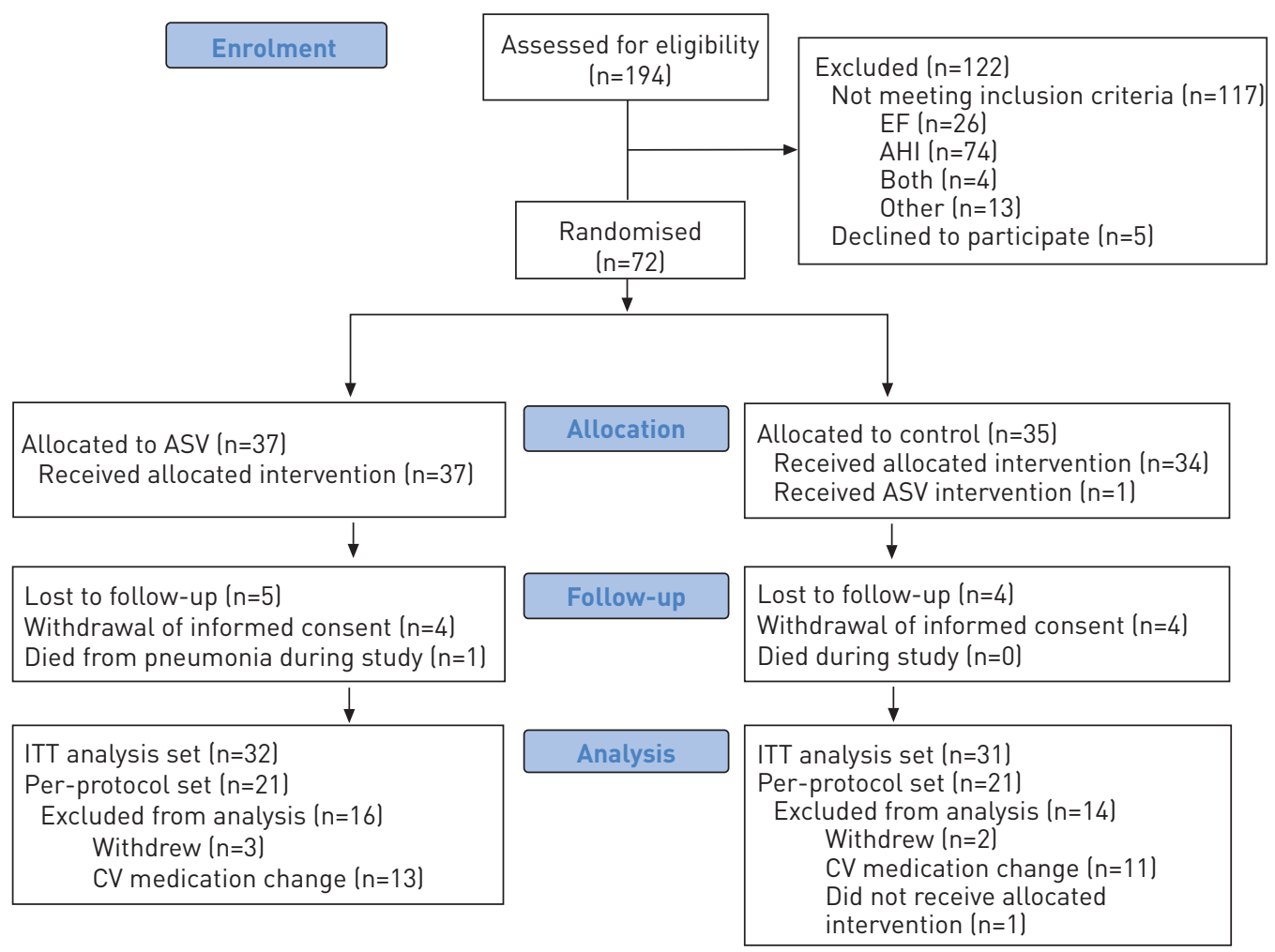

FIGURE 1 Trial Flow. EF: ejection fraction; AHI: apnoea/hypopnoea index; ITT: intention-to-treat; CV: cardiovascular; ASV: auto-servoventilation.

between-group differences of the week 12 values (adjusted for possible baseline differences with a linear regression) and the change in value within 12 weeks of treatment (independent samples t-test). Changes throughout the study within one group were assessed with the paired samples t-test. All statistical analyses, apart from the primary end-point, were performed in an explorative manner and no multiplicity adjustment of the p-values was performed. All primary and secondary end-point analyses were first performed on the ITT population and then repeated on the PP population. In the ITT population, the change in LVEF was also analysed by the type of SDB. In the PP analysis all secondary end-points were analysed by the type of SDB. All statistical tests were two-sided with a significance level of $5 \%$. All statistical analyses were performed with SPSS 18.0 (SPSS Inc., Chicago, IL, USA).

\section{Results}

Trial flow

A total of 194 patients were screened for eligibility (fig. 1). After excluding the majority of them due to an AHI $<20$ events $\cdot h^{-1}$ or LVEF $>40 \%, 72$ patients were randomised to receive ASV $(n=37)$ or to the control group $(n=35)$. All patients received the treatment they were allocated, except for one control patient who was treated with ASV.

The ITT analysis set consists of all 72 randomised patients in their randomised groups (fig. 1). The PP analysis set contained 21 patients in the ASV group and 21 patients in the control group. Reasons for exclusion were: early withdrawal; one patient from the control group who was treated with ASV; and cardiovascular medication change, in order to avoid bias from competing therapies.

\section{Patients}

Table 1 shows the similarity in the baseline characteristics of the two groups. As expected, the majority of the patients were middle-aged males. The only significant difference was in body mass index, which was lower in the ASV group (table 1). The proportion of patients using cardiac medication is shown in table 1 and did not change significantly during the follow-up period. One patient from the control group had a $\beta$ receptor blocker added to their medication and in two patients from the ASV group, spironolactone was discontinued. The occurrence of serious adverse events was similar between the groups (table 2). 


\section{TABLE 1 Baseline characteristics}

\begin{tabular}{|c|c|c|}
\hline & ASV & Control \\
\hline Subjects $\mathrm{n}$ & 37 & 35 \\
\hline Age years & $64 \pm 10$ & $65 \pm 9$ \\
\hline Males & $34(92)$ & $32(91)$ \\
\hline $\mathrm{BMI}^{\#} \mathrm{~kg} \cdot \mathrm{m}^{-2}$ & $28.9 \pm 4.3$ & $31.6 \pm 4.9$ \\
\hline Systolic BP mmHg & $119 \pm 15$ & $118 \pm 17$ \\
\hline Diastolic BP $\mathrm{mmHg}$ & $70 \pm 11$ & $70 \pm 9$ \\
\hline Heart rate beats $\cdot \min ^{-1}$ & $70 \pm 11$ & $69 \pm 11$ \\
\hline NYHA class II & $28(76)$ & $26(74)$ \\
\hline NYHA class III & $9(24)$ & $9(26)$ \\
\hline \multicolumn{3}{|l|}{ Cause of heart failure } \\
\hline Ischaemic & $19(51)$ & $20(57)$ \\
\hline Nonischaemic & $18(49)$ & $15(43)$ \\
\hline \multicolumn{3}{|l|}{ Rhythm and pacing } \\
\hline History of atrial fibrillation & $10(27)$ & $15(43)$ \\
\hline Biventricular pacemaker & $3(8)$ & $6(17)$ \\
\hline Implanted cardiac defibrillator & $16(43)$ & $17(49)$ \\
\hline \multicolumn{3}{|l|}{ Medication } \\
\hline Diuretic & $24(65)$ & $32(91)$ \\
\hline Spironlactone & $18(49)$ & $18(51)$ \\
\hline ACE inhibitor & $27(73)$ & $24(69)$ \\
\hline Angiotensin-receptor blocker & $12(32)$ & $9(26)$ \\
\hline$\beta$-receptor blocker & $29(78)$ & 32 (91) \\
\hline
\end{tabular}

Data are presented as mean \pm SD or $n(\%)$, unless otherwise stated. ASV: auto-servoventilation; BMI: body mass index; BP: blood pressure; NYHA: New York Heart Association; ACE: angiotensin-converting enzyme. ${ }^{\#}: \mathrm{p}=0.017$ using an independent samples t-test.

\section{Intervention}

Bi-level positive airway pressure daytime test

When IPS, in addition to expiratory positive airway pressure (mean $8.1 \pm 1.7 \mathrm{cmH}_{2} \mathrm{O}$ ), was raised from 0 to $10 \mathrm{cmH}_{2} \mathrm{O}$, neither systolic, diastolic or mean $\mathrm{BP}$, or mean heart rate changed significantly with expiratory positive airway pressure and IPS $(\mathrm{p}=0.93, \mathrm{p}=0.96, \mathrm{p}=0.92$ and $\mathrm{p}=0.88$, respectively) (online supplementary fig. E1). Five patients terminated the bi-level positive airway pressure daytime test early due to discomfort because of pressure intolerance. In one patient, the mean BP dropped to $58 \mathrm{mmHg}$ at an end expiratory positive airway pressure of $15 \mathrm{cmH}_{2} \mathrm{O}$ plus $8 \mathrm{cmH}_{2} \mathrm{O}$ IPS. Until termination of the daytime test, none of the patients experienced symptoms of haemodynamic compromise.

\section{ITT analysis}

ASV settings and compliance

Daily device use was $4.5 \mathrm{~h}$ on a mean expiratory positive airway pressure of $8.1 \pm 1.7 \mathrm{cmH}_{2} \mathrm{O}$ and the maximum inspiratory positive airway pressure was set at a mean of $14.0 \pm 5.3 \mathrm{cmH}_{2} \mathrm{O}$. Automatic backup rate was used in all patients.

\section{Primary outcome}

The change in LVEF, the primary end-point of the study, was similar in the ASV and control patients with both arms showing a modest improvement $(2.8 \pm 5.5$ versus $2.3 \pm 6.5 \% ; \mathrm{p}=0.767)$ (table 3$)$. The primary end-point was analysed according to the four participating study centres in order to rule out centre or country bias. In all centres the change in LVEF was similar in the ASV and control patients (Regensburg: $\mathrm{n}=23, \mathrm{p}=0.964$; Laval: $\mathrm{n}=31, \mathrm{p}=0.557$; Clamart: $\mathrm{n}=7, \mathrm{p}=0.918$; Swansea: $\mathrm{n}=9, \mathrm{p}=0.472$ ).

In the sub-analyses of patients with OSA $(n=36)$ and CSA $(n=32)$, the change in LVEF was not significantly different between the ASV and the control group (OSA: $3.0 \pm 5.4$ versus $1.8 \pm 6.9 \%$; CSA: $2.5 \pm 5.8$ versus $3.0 \pm 6.2 \% ; \mathrm{p}>0.05$ for both comparisons).

\section{Secondary outcomes}

In the ASV group, AHI and central AHI were significantly decreased compared to the control group (table 3). Mean arterial oxygen saturation $\left(\mathrm{SaO}_{2}\right)$ increased significantly in the ASV group compared with the control group (table 3), indicating that ASV effectively suppressed SDB. 


\begin{tabular}{lcc} 
& ASV & Control \\
\hline Serious adverse event & $6(16)$ & $7(20)$ \\
Cardiac worsening & $3(8)$ & $5(14)$ \\
Death during study & $1(3)^{\#}$ & $0(0)$ \\
Other & $2(5)$ & $2(6)$ \\
$\quad$ Lung cancer & 0 & 1 \\
DVT/PE & 1 & 0 \\
Duodenal ulcer & 0 & 1 \\
Foot ulcer & 1 & 0 \\
\hline
\end{tabular}

Data are presented as $\mathrm{n}(\%)$ or $\mathrm{n}$. ASV: auto-servoventilation; DVT: deep vein thrombosis; PE: pulmonary embolism. " : pneumonia.

There were statistically nonsignificant trends for a fall in NT-proBNP and a rise in GFR in the ASV group compared with the control group $\left(-431 \mathrm{ng} \cdot \mathrm{mL}^{-1}, \mathrm{p}=0.064\right.$ and $5.52 \mathrm{~mL} \cdot \mathrm{min}^{-1} \cdot 1.73 \mathrm{~m}^{-2}, \mathrm{p}=0.076$, respectively) (table 3$)$. The changes in all other secondary outcomes, including general and disease-specific QoL and symptoms, were similar between the groups (table 3).

\section{PP analysis}

Primary outcome

There were moderate improvements between baseline and 3 month values of LVEF in both the ASV and control arms, but the between-group differences were again similar $(3.8 \pm 5.0 \%$ versus $4.1 \pm 6.8 \%$; $p=0.915)$ (fig. 2c). In the ASV group the change in AHI between baseline and 12 weeks was not significantly related to changes in LVEF (linear regression analysis $\mathrm{R}^{2}=0.029 ; \mathrm{p}=0.52$ ).

\section{Secondary outcomes}

There were significant reductions in the AHI and central AHI, and a rise in mean $\mathrm{SaO}_{2}$ on ASV therapy (fig. $2 \mathrm{a}$ and b). There was a significant decrease in NT-proBNP in the ASV group compared with the control group $\left(-372 \pm 581 \mathrm{ng} \cdot \mathrm{mL}^{-1}\right.$ versus $\left.142 \pm 640 \mathrm{ng} \cdot \mathrm{mL}^{-1}, \mathrm{p}=0.010\right)$ (online supplementary table E1

\section{TABLE 3 Outcome measures: intention-to-treat analysis set}

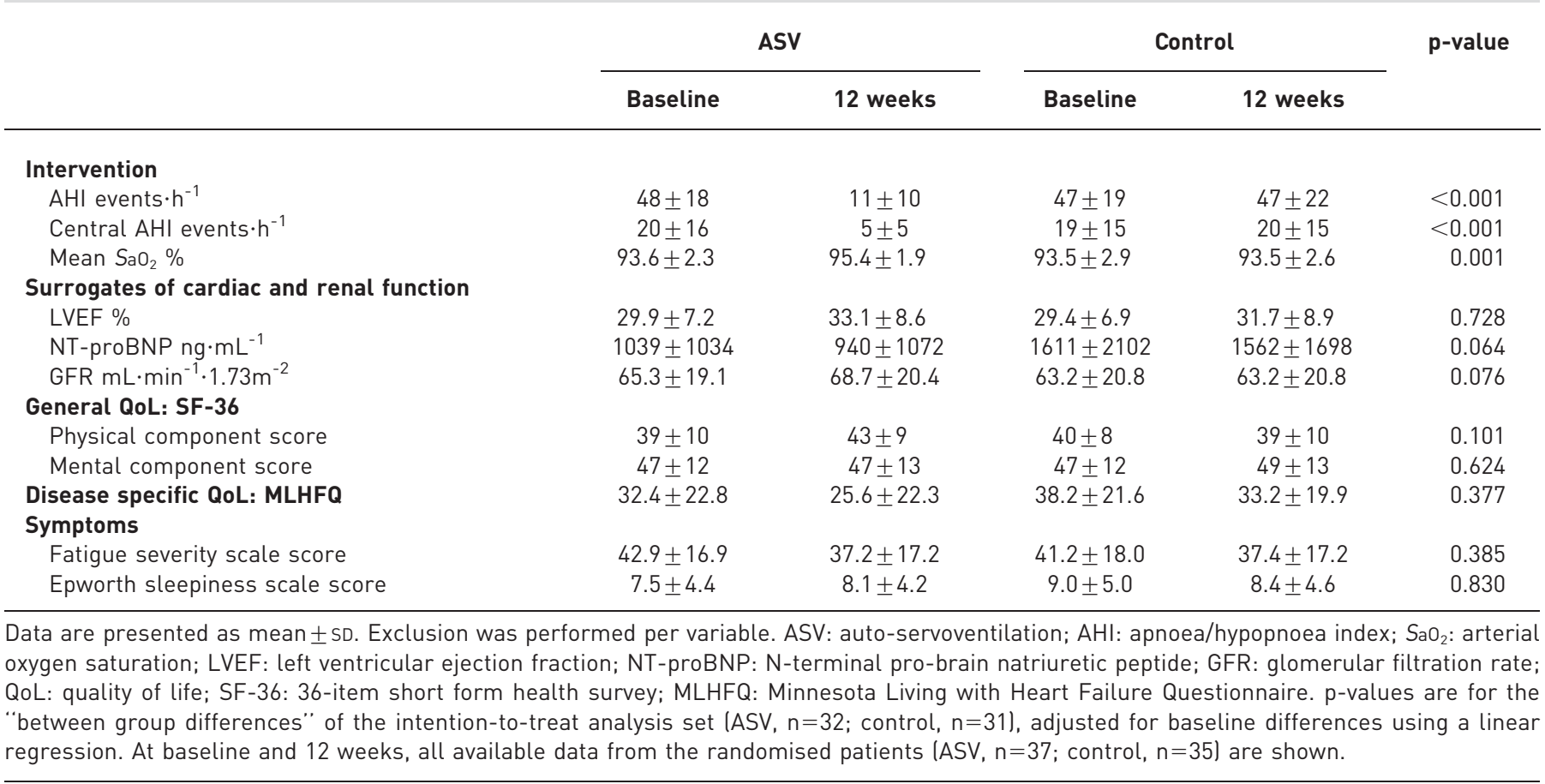



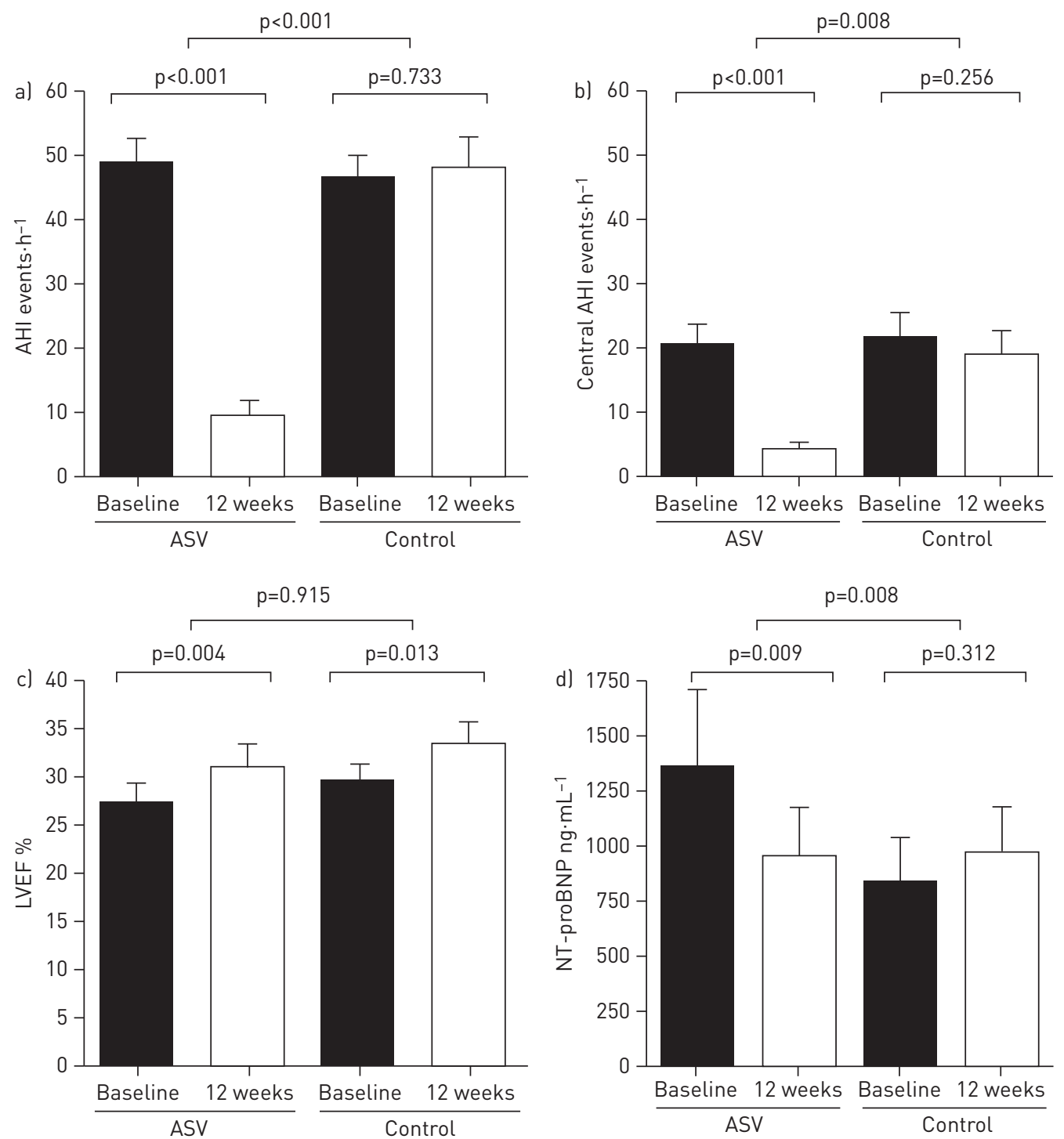

FIGURE 2 Effects of auto-servoventilation (ASV) on a) apnoea/hypopnoea index (AHI), b) central AHI, c) left ventricular ejection fraction (LVEF) and d) N-terminal pro-brain natriuretic peptide (NT-proBNP) in the per-protocol dataset.

and fig. 2d). p-values were adjusted for baseline differences. GFR was similar between the groups and showed no statistically significant change over time.

Three of the eight subscores of the SF-36 questionnaire (Social Functioning, Bodily Pain and General Health) showed statistically significant improvements in the ASV group compared with the control group ( $\mathrm{p}=0.011, \mathrm{p}=0.019$ and $\mathrm{p}=0.013$, respectively). The change in the physical and the mental component score of the SF-36 was not different between the ASV and control groups (online supplementary fig. E2).

A larger reduction in MLHFQ total score was observed in the active treatment group (-8.2 \pm 16.4$)$ than in the control group $(-1.15 \pm 15.0)$ (online supplementary fig. E2). This difference was not statistically significant due to the large variation of the scores. While the Epworth sleepiness scale score remained similar in both the ASV and control group, there was a nonsignificant reduction of the fatigue severity scale upon ASV therapy (online supplementary fig. E2).

\section{Subanalysis in patients with CSA and OSA}

Of the PP population, 21 patients had predominantly OSA, of whom 10 were randomised to the ASV and 11 to the control group; 21 patients had predominantly CSA, of whom 11 were allocated to the ASV and 10 to the control group. The change of LVEF from baseline to 12 weeks was similar in the ASV and control 
group in both the OSA and the CSA patients, respectively (OSA: $3.6 \pm 3.5 \%$ versus $4.6 \pm 6.9 \%, \mathrm{p}>0.05$; CSA: $3.7 \pm 6.3 \%$ versus $3.4 \pm 7.0 \%, \mathrm{p}>0.05)$. The effects of ASV on secondary outcomes in the OSA and CSA patients were similar to the results in the entire PP population.

\section{Effects of treatment adherence to ASV}

For this prespecified analysis, the ASV group was stratified into groups with $\geqslant 4$ and $<4 \mathrm{~h}$ use of the ASV device per night, respectively. The control, ASV use $<4 \mathrm{~h}$ and ASV use $\geqslant 4$ h groups had an increasing time of intervention per night $(0,0.56$ and $4.76 \mathrm{~h})$. In association with this increasing time of ASV use, there were stepwise trends towards greater improvements in NT-proBNP, GFR, the physical component score of the SF-36 questionnaire and the fatigue severity scale (fig. 3).

\section{Discussion}

The major findings of this randomised, multicentre, open label, parallel group trial of ASV therapy in patients with CHF and SDB are 1) that ASV effectively suppressed SDB (both CSA and OSA) and adherence to this therapy was satisfactory at $4.5 \mathrm{~h}$ per night; 2) ASV was not associated with an improvement of LVEF, the primary outcome, but was associated with a significant fall of NT-proBNP, a surrogate for cardiac loading conditions and cardiac function in the PP analysis; 3) ASV did not significantly influence GFR, general and disease-specific QoL, or symptoms of fatigue and sleepiness.
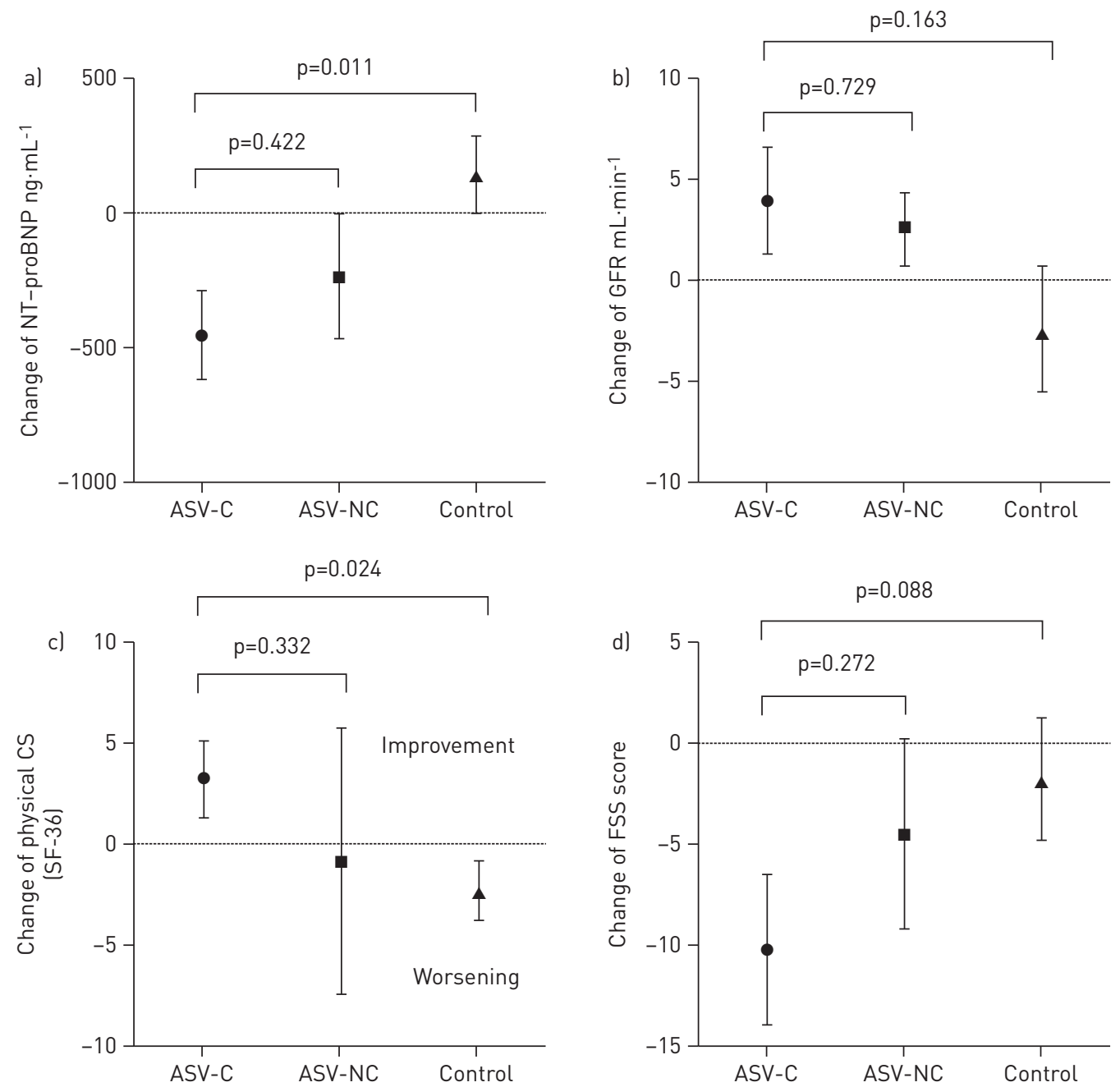

FIGURE 3 Effects of the duration of auto-servoventilation use in changes of outcome measures from baseline to 12 weeks in the per-protocol dataset. a) N-terminal pro-brain natriuretic peptide (NT-proBNP), b) glomerular filtration rate (GFR), c) physical component score (CS) of the 36-item short form health survey (SF-36) and d) fatigue severity scale (FSS). ASV-C: auto-servoventilation compliant (defined as $\geqslant 4 \mathrm{~h}$ device use per night); ASV-NC: auto-servoventilation non-compliant (defined as $<4$ h device use per night). 
In line with previous studies, ASV proved to be an efficient treatment for coexisting CSA and OSA in patients with CHF $[13-15,17,20,25]$. In addition, the observed ASV use of $4.5 \mathrm{~h}$ per night is similar to other short and mid-term ASV trials, where the usage range was 4.2-5.2 h per night $[13,15,17,25]$. Considering the relatively short sleep duration of CHF patients [26], the adherence levels obtained in this trial could be considered satisfactory.

The present trial was powered to detect significant differences in the primary end-point LVEF; however, neither the ITT nor the PP analysis showed significantly greater improvement of LVEF in the ASV group compared with the control group. In the ASV group the change of AHI between baseline and 12 weeks was not significantly related with changes in LVEF. Thus, the data of the present study concur with previous trials that did not find a significant effect of ASV on LVEF in CHF patients with SDB $[15,16,27]$ compared to control interventions (e.g. optimal medical management alone or other forms of positive airway pressure therapy). In contrast, PHILIPPE et al. [17] found a significant increase in LVEF of 7\% in a small subset of seven CSA patients treated with ASV. Similarly, HASTINGS et al. [25] observed, in a non-randomised trial of ASV in CHF patients with CSA, an increase in LVEF of 6\%. Recently, in a 3 month randomised trial comparing the effects of ASV and CPAP in CHF patients with coexisting CSA and OSA, KASAI et al. [13] observed a significant improvement of LVEF in patients using ASV $(n=16)$ compared with CPAP $(+9.1 \%$ versus $+1.9 \%$, respectively). SHARMA et al. [28] recently studied the effects of ASV on LVEF compared to a control intervention in a meta-analysis including six non-randomised and four randomised trials. Including all studies ASV did significantly improve LVEF. However, this result is mainly based on the nonrandomised trails, while in randomised trials the effects of ASV on LVEF are modest $(<2 \%)$ [28]. Study design appears to have an influence on effect size, while no specific characteristics of patients who may have the greatest improvement of LVEF on ASV could be identified [28].

There was a significant reduction of NT-proBNP in the ASV group and an increase in the control group. Such effects cannot be explained by changes in pharmacological therapy or renal function in the present study, as these potential confounders did not change significantly. One possibility is that ASV improved cardiac preload and afterload, which could lead to a reduction of cardiac morbidity [29]. The observed effect size is similar to the $23 \%$ reduction of BNP that was found in a previous randomised crossover trial after a 4-week ASV treatment period in CHF patients with CSA [16], but less than has been observed with cardiac resynchronisation therapy (42\% in association with an increase of LVEF) [30].

One potential reason for the finding that ASV does improve NT-proBNP and does not improve LVEF, compared with the control group, could be the time of day blood was drawn (morning) and echocardiography (time of day was not predefined) was performed. When observing studies of CPAP in OSA patients, the greatest effects on blood pressure [31] are present in the morning hours. A similar dissociation of effects of ASV on BNP and LVEF in CHF patients and CSA [16] or CSA with coexisting OSA [27] was observed previously.

In accordance with the findings of PEPPERELL et al. [16], we did not observe significant effects of ASV on general and disease-specific QoL. In contrast, PHILIPPE et al. [17] demonstrated an improvement in diseasespecific QoL as assessed with the MLHFQ after 6 months of ASV treatment. However, as in the present study, this effect was not observed at 3 months [17].

As reported in the literature, patients in the present study did not report excessive daytime hypersomnolence at baseline [26, 32-34], thus no significant change of this symptom was observed. However, fatigue was observed at baseline, as indicated by a fatigue severity scale score of $>36$ [35], and a nonsignificant fall was observed after 3 months of ASV therapy, bringing this score back into the normal range. Fatigue has not been evaluated in comparable intervention trials.

This trial has several strengths and limitations. To optimise data quality, polysomnography recordings from all centres were centrally scored by two experienced sleep technicians at the University of Pennsylvania (Philadelphia, PA, USA), who were blinded to the clinical data of the patients. Most other trials in this field have been single centre $[16,19,25,27,33,36]$. In addition, all patients in the present study were on contemporary cardiac medication [2], which has developed considerably in recent years.

One limitation of the study is that some patients had a competitive therapy during the trial period (change in cardiac medication); such patients had to be excluded from the PP analysis. For example, after cardiac worsening ( $n=3$ in the ASV group and $n=5$ in the control group) patients received intensified diuretic treatment, leading to improvement of cardiac function. Thus, although the present study is, to date, the largest randomised controlled trial of ASV in CHF patients with SDB assessing cardiac function, the PP analysis did not comply with the calculated sample size. Therefore, the trial lacked the necessary power to reliably address the effects on several of the outcome measures and to perform important sub-analyses, such as whether effect sizes depend on age or cause of heart failure. 
However, a stepwise trend towards greater improvements in GFR, general QoL (physical component score) and fatigue in the group of patients who complied with ASV therapy, suggest that these outcomes should be re-evaluated in larger trials.

In summary, this trial supports the notion that ASV is an effective treatment for both CSA and OSA in patients with CHF. Despite the lack of SDB-related symptoms in this group of patients, adherence to ASV therapy was satisfactory in most patients. ASV in CHF patients with SDB reduces NT-proBNP levels, as a surrogate for improvement of cardiac loading conditions and function. These changes were not associated with greater improvement of LVEF in the ASV group compared wih the control group. There were no significant improvements in QoL or symptoms. The results support that CHF patients with CSA and OSA, with no or mild SDB-related symptoms, can be randomised in large scale long-term trials of positive airway pressure therapy versus control in order to determine whether positive airway pressure therapy can improve cardiovascular outcome in such patients.

\section{References}

1 Redfield MM, Jacobsen SJ, Burnett JC Jr, et al. Burden of systolic and diastolic ventricular dysfunction in the community: appreciating the scope of the heart failure epidemic. JAMA 2003; 289: 194-202.

2 Dickstein K, Cohen-Solal A, Filippatos G, et al. ESC guidelines for the diagnosis and treatment of acute and chronic heart failure 2008: the Task Force for the diagnosis and treatment of acute and chronic heart failure 2008 of the European Society of Cardiology. Developed in collaboration with the Heart Failure Association of the ESC (HFA) and endorsed by the European Society of Intensive Care Medicine (ESICM). Eur J Heart Fail 2008; 10: 933-989. Jessup M, Brozena S. Heart failure. N Engl J Med 2003; 348: 2007-2018.

4 Cubbon RM, Gale CP, Kearney LC, et al. Changing characteristics and mode of death associated with chronic heart failure due to left ventricular systolic dysfunction: a study across therapeutic eras. Circ Heart Fail 2011; 4: 396-403.

5 Levy D, Kenchaiah S, Larson MG, et al. Long-term trends in the incidence of and survival with heart failure. $N$ Engl J Med 2002; 347: 1397-1402.

6 Javaheri S, Parker TJ, Liming JD, et al. Sleep apnea in 81 ambulatory male patients with stable heart failure. Types and their prevalences, consequences, and presentations. Circulation 1998; 97: 2154-2159.

Schulz R, Blau A, Borgel J, et al. Sleep apnoea in heart failure. Eur Respir J 2007; 29: 1201-1205.

8 Javaheri S, Shukla R, Zeigler H, et al. Central sleep apnea, right ventricular dysfunction, and low diastolic blood pressure are predictors of mortality in systolic heart failure. J Am Coll Cardiol 2007; 49: 2028-2034.

9 Jilek C, Krenn M, Sebah D, et al. Prognostic impact of sleep disordered breathing and its treatment in heart failure: an observational study. Eur J Heart Fail 2011; 13: 68-75.

10 Wang H, Parker JD, Newton GE, et al. Influence of obstructive sleep apnea on mortality in patients with heart failure. J Am Coll Cardiol 2007; 49: 1625-1631.

11 Bradley TD, Logan AG, Kimoff RJ, et al. Continuous positive airway pressure for central sleep apnea and heart failure. N Engl J Med 2005; 353: 2025-2033.

12 Arzt M, Floras JS, Logan AG, et al. Suppression of central sleep apnea by continuous positive airway pressure and transplant-free survival in heart failure: a post hoc analysis of the Canadian Continuous Positive Airway Pressure for Patients with Central Sleep Apnea and Heart Failure Trial (CANPAP). Circulation 2007; 115: 3173-3180.

13 Kasai T, Usui Y, Yoshioka T, et al. Effect of flow-triggered adaptive servo-ventilation compared with continuous positive airway pressure in patients with chronic heart failure with coexisting obstructive sleep apnea and CheyneStokes respiration. Circ Heart Fail 2010; 3: 140-148.

14 Randerath WJ, Galetke W, Kenter M, et al. Combined adaptive servo-ventilation and automatic positive airway pressure (anticyclic modulated ventilation) in co-existing obstructive and central sleep apnea syndrome and periodic breathing. Sleep Med 2009; 10: 898-903.

15 Fietze I, Blau A, Glos M, et al. Bi-level positive pressure ventilation and adaptive servo ventilation in patients with heart failure and Cheyne-Stokes respiration. Sleep Med 2007; 9: 652-659.

16 Pepperell JC, Maskell NA, Jones DR, et al. A randomized controlled trial of adaptive ventilation for Cheyne-Stokes breathing in heart failure. Am J Respir Crit Care Med 2003; 168: 1109-1114.

17 Philippe C, Stoïca-Herman M, Drouot X, et al. Compliance with and effectiveness of adaptive servoventilation versus continuous positive airway pressure in the treatment of Cheyne-Stokes respiration in heart failure over a six month period. Heart 2006; 92: 337-342.

18 Maisel AS, Krishnaswamy P, Nowak RM, et al. Rapid measurement of B-type natriuretic peptide in the emergency diagnosis of heart failure. N Engl J Med 2002; 347: 161-167.

19 Mansfield DR, Gollogly NC, Kaye DM, et al. Controlled trial of continuous positive airway pressure in obstructive sleep apnea and heart failure. Am J Respir Crit Care Med 2004; 169: 361-366.

20 Arzt M, Wensel R, Montalvan S, et al. Effects of dynamic bilevel positive airway pressure support on central sleep apnea in men with heart failure. Chest 2008; 134: 61-66.

21 Lang RM, Bierig M, Devereux RB, et al. Recommendations for chamber quantification: a report from the American Society of Echocardiography's Guidelines and Standards Committee and the Chamber Quantification Writing Group, developed in conjunction with the European Association of Echocardiography, a branch of the European Society of Cardiology. J Am Soc Echocardiogr 2005; 18: 1440-1463.

22 Jenkinson C, Gray A, Doll H, et al. Evaluation of index and profile measures of health status in a randomized controlled trial. Comparison of the Medical Outcomes Study 36-Item Short Form Health Survey, EuroQol, and disease specific measures. Med Care 1997; 35: 1109-1118.

23 Rector TS, Cohn JN. Assessment of patient outcome with the Minnesota Living with Heart Failure questionnaire: reliability and validity during a randomized, double-blind, placebo-controlled trial of pimobendan. Pimobendan Multicenter Research Group. Am Heart J 1992; 124: 1017-1025.

24 Krupp LB, LaRocca NG, Muir-Nash J, et al. The fatigue severity scale. Application to patients with multiple sclerosis and systemic lupus erythematosus. Arch Neurol 1989; 46: 1121-1123. 
Hastings PC, Vazir A, Meadows GE, et al. Adaptive servo-ventilation in heart failure patients with sleep apnea: a real world study. Int J Cardiol 2008; 139: 17-24.

26 Arzt M, Young T, Finn L, et al. Sleepiness and sleep in patients with both systolic heart failure and obstructive sleep apnea. Arch Intern Med 2006; 166: 1716-1722.

27 Randerath WJ, Nothofer G, Priegnitz C, et al. Long-term auto-servoventilation or constant positive pressure in heart failure and coexisting central with obstructive sleep apnea. Chest 2012; 142: 440-447.

28 Sharma BK, Bakker JP, McSharry DG, et al. Adaptive servoventilation for treatment of sleep-disordered breathing in heart failure: a systematic review and meta-analysis. Chest 2012; 142: 1211-1221.

29 Richards AM, Nicholls MG, Yandle TG, et al. Plasma N-terminal pro-brain natriuretic peptide and adrenomedullin: new neurohormonal predictors of left ventricular function and prognosis after myocardial infarction. Circulation 1998; 97: 1921-1929.

30 Fruhwald FM, Fahrleitner-Pammer A, Berger R, et al. Early and sustained effects of cardiac resynchronization therapy on N-terminal pro-B-type natriuretic peptide in patients with moderate to severe heart failure and cardiac dyssynchrony. Eur Heart J 2007; 28: 1592-1597.

31 Becker HF, Jerrentrup A, Ploch T, et al. Effect of nasal continuous positive airway pressure treatment on blood pressure in patients with obstructive sleep apnea. Circulation 2003; 107: 68-73.

32 Bradley TD, Floras JS. Obstructive sleep apnoea and its cardiovascular consequences. Lancet 2009; 373: 82-93.

33 Kaneko Y, Floras JS, Usui K, et al. Cardiovascular effects of continuous positive airway pressure in patients with heart failure and obstructive sleep apnea. N Engl J Med 2003; 348: 1233-1241.

34 Redeker NS, Muench U, Zucker MJ, et al. Sleep disordered breathing, daytime symptoms, and functional performance in stable heart failure. Sleep 2010; 33: 551-560.

35 Taylor RR, Jason LA, Torres A. Fatigue rating scales: an empirical comparison. Psychol Med 2000; 30: 849-856.

36 Sin DD, Logan AG, Fitzgerald FS, et al. Effects of continuous positive airway pressure on cardiovascular outcomes in heart failure patients with and without Cheyne-Stokes respiration. Circulation 2000; 102: 61-66. 